\title{
Livelihood Vulnerability Assessment to Climate Change at Community Level Using Household Survey: A Case Study from Nam Dinh Province, Vietnam
}

Phan The Cong

Vietnam University of Commerce, Email: congpt@vcu.edu.vn

Dang Huu Manh

Hanoi University of Natural Resources and Environment, Email: dhmanh@hunre.edu.vn

Hoang Anh Huy

Hanoi University of Natural Resources and Environment, Email: hahuy@hunre.edu.vn

Tran Thi Ly Phuong

University of Economic and Business, Email: phuonglyktpt@gmail.com

Luong Thi Tuyen

Hanoi University of Natural Resources and Environment, Email: tuyenlt.vnu@gmail.com

Doi:10.5901/mjss.2016.v7n3s1p358

\section{Abstract}

\begin{abstract}
Vietnam was ranked 6th among countries deemed vulnerable to climate change based on Climate Risk Index (CRI) during 1991 - 2010. Damage caused by extreme weather events such as storms, floods for coastal communities in Vietnam increases significantly each year. Objective of this study is to investigate climate change adaptation strategies for livelihoods of coastal communities in Rang Dong town, Nghia Hung district, Nam Dinh province, Vietnam. Sustainable Livelihood Framework of DIFID was used to analyse existing livelihoods and adaptation strategies of coastal residents. Interviews were conducted with 79 households in Rang Dong town focusing on livelihood assets that can help them to adapt to climate change. Results indicate that adaptation capacity of households was at a low level based on availability of their livelihood assets. Financial, physical and human capital still showed much weakness and awareness of residents about climate change was low. Natural capital has been reduced by the impacts of climate change. Additionally, results also revealed that respondents have not taken activities and solutions to reduce impacts of climate change causing for the health, water and actions of livelihoods. On that basis, the research provides some recommendations, which are made for policy makers to improve the ability to cope of coastal residents to the effects of climate change.
\end{abstract}

Keywords: Climate change, Adaptation, Vulnerability, Livelihoods, Vietnam.

\section{Introduction}

Vietnam is one of the most vulnerable countries to climate change in the South East Asia (Yusuf and Francisco 2009). Vietnam ranked sixth in the Climate Risk Index (CRI) in period 1991-2010 and 23rd in the Climate Change Vulnerability Index (CCVI) in 2012 (Harmeling 2012, Maplecroft 2012). Among the 84 coastal developing countries investigated in terms of sea level rise (SLR), Vietnam ranks first in terms of impact on population, GDP, urban extent, and wetland areas, and ranks second in terms of impact on land area (behind the Bahamas) and agriculture (behind Egypt) (Dasgupta et al. 2009). According to Giang (2005), in the period from 1994-2003, average damage by natural disasters for Vietnam was estimated about 250 million USD, accounted for about 0.8\% GDP annually. Osterblom et al. (2013) argues that "Human activities have substantial impacts on marine ecosystems, including rapid regime shifts with large consequences for human well-being". The concept of social-ecological system is based on the need to reconnect nature and society by considering not only intrinsic but also instrumental values (Folke et al. 2005). The concept of resilience has been 
introduced by (Holling 1973) which is further developed by several studies specially Carol Floke, who says that resiliencebuilding management is flexible and open to learning (Folke et al. 2002). The socio-ecological system with high resilience indicates a better sustainability. Adaptive governance in mitigation of climate change impact can ensure resilience building management which incorporates different stakeholders' (different level of governments, NGOs, fishers, local people) views, values, their expectations to the policy (Folke et al. 2005, Ostrom 2009, Österblom et al. 2011). Therefore, when developing strategies to adapt to climate change, in addition to reviewing issues related to the impact of climate change, it also needs the full awareness of adaptability. ADB (2014) has reviewed the general research about the impact of climate change in the Southeast Asia region. This report reviews the economics of climate change, with a particular focus on Indonesia, the Philippines, Singapore, Thailand, and Viet Nam. It confirms that Southeast Asia will be one of the most vulnerably affected regions by climate change due to high population density and strongly depending on agriculture, natural resources and forestry. The advantage of this study is to investigate a wide range of adaptation measures already being applied and their great potentials to contribute to the reduction of positive impacts of climate change by using data to predict vulnerable effects to 2100 . It also shows that the cost to the region and globally of taking no early action against climate change far outweighs the cost of action. The report urges Southeast Asia to play an important part in working toward a global solution to climate change, and to apply all feasible and economically viable adaptation and mitigation measures as key elements of poverty reduction and sustainable development strategies. Research by ECLAC (2011) is a part of the comprehensive research project on the Caribbean. The results of the study provide inputs for comment on the impact of the economy under climate change in Caribbean. The main objective of the study is to evaluate and estimate the impact of climate change on agriculture sector in Guyana and the cost implications for these impacts. The advantage of this study is providing model to estimate the historical relationship between the outputs of agriculture and the conditions of the variables related to the production. The model was used to predict the impact of climate change on selected sub-sectors in the agriculture sector. Research by Adger (1999) discusses methods assessing vulnerability caused by climate change and clarifies the relationship between the concept of vulnerability and adaptation. From that result, this research is the basic knowledge for us to consider the vulnerability and adaptive capacity in the study. The relevant studies have provided a lot of information on issues related to climate change, the impacts of climate change, people's perception and adaptation measures. This study will focus on analyzing the impact of natural disasters and climate change on livelihoods and adaptive capacities of people through the sustainable livelihoods framework in the Rang Dong town, Nghia Hung district, Nam Dinh province. The following specific objectives will be carried out: (1) Investigating the awareness of people in the town of Rang Dong, Nghia Hung district, Nam Dinh province about the impact of climate change; (2) Evaluating the adaptability to climate change of coastal communities in Rang Dong town; (3) Proposing some recommendations for policy makers, planners, and farmers to help people with alternative livelihood strategies to adapt to climate change.

\section{Research Methodology}

\subsection{Data collection methods}

In-depth interviews for 79 households living in the Rang Dong town were conducted from $16^{\text {th }}$ January in 2013 to $20^{\text {th }}$ January in 2013 with the purpose of collecting detailed information about the 5 groups of factors affecting household livelihoods including: livelihood assets, livelihood strategies, livelihood outcomes, the institutional and policy, and external context. And the livelihood assets include natural capital (land, forests, marine resources, water, air, biodiversity, etc.); physical capital (roads, housing, water supply and drainage, energy, information), financial capital (savings, cash, jewelry, loans, earnings, etc.); human capital (skills, knowledge, experience, education, health, etc.); social capital which involve in the relationship between a group of people in society to do livelihood activities, including society system (politics and civil organization), member of social organization, target market... Livelihood assets are considered as adaptation strategies for coastal communities.

The area of research is Nghia Hung located in the southern coast of the Red River Delta. The total population is about 200 thousand people. Traditional agriculture, animal husbandry especially coastal aquaculture are the major occupation of the local people. The official statistics of 2012 showed that the total cultivated area was 22138 ha and aquaculture area was $2840 \mathrm{ha}^{1}$.

\footnotetext{
${ }_{1}^{1}$ Report no. 81-BC/HU Nghia Hung District Council
} 

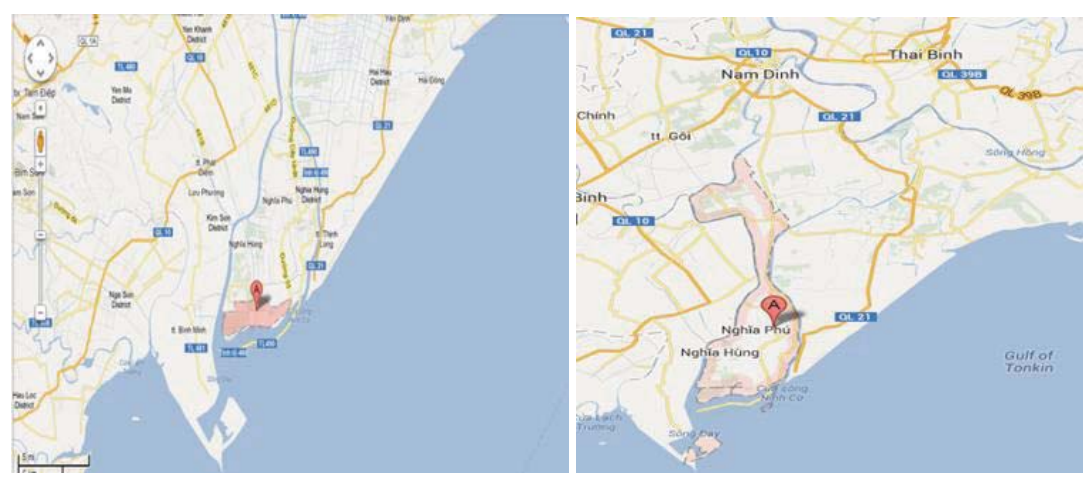

Figure 1: Position of Nghia Hung District, Rang Dong town.

Source: Googlemap.com

\subsection{Data analysis methods}

The sustainable livelihoods framework was applied to analyze the frame.

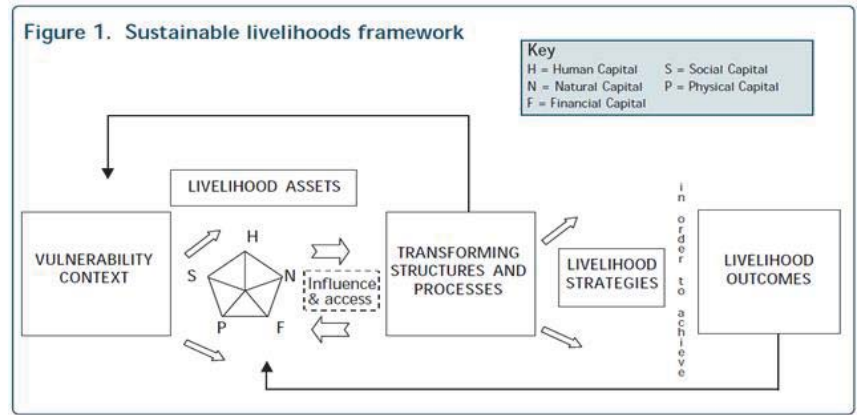

Figure 1: Sustainable livelihoods framework

Source: DFID, 2001

Basically, the sustainable livelihoods framework will analyze the interaction of the 5 groups of factors affecting household livelihoods including: livelihood assets, livelihood strategies, livelihood outcomes, the institutional and policy, and external context as mentioned above.

The IPPC livelihood vulnerability assessment framework was used to analyze the data (IPCC 2001). In this framework, vulnerability $(\mathrm{V})$ is defined as the extent to which a natural or social system is susceptible to sustaining damage from climate change. $V$ is expressed mathematically as a function of exposure (E), sensitivity (S), and adaptive capacity (AC):

$V=f(E, S, A C)$

Of which: $E$ is defined as the degree of exposure of the system to climatic hazards. $S$ is defined as the degree to which a system will respond to a given change in climate, including beneficial and harmful effects. AC is defined as the degree to which adjustments in practices, processes, or structures can moderate or offset the potential for damage or take advantage of opportunities created by a given change in climate. In this study, components of these factors are expressed in table 1. 
Table 1: Vulnerability framework

\begin{tabular}{|l|l|l|}
\hline Exposure & Sensitivity & Adaptability \\
\hline Storms & Percentage of the population depends & The poverty rate \\
\hline Flood & The illiteracy rate & Property Index \\
\hline Drought & Percentage of women & The rate of permanent houses \\
\hline Coastal cyclones & Standardized household size & Adaptation strategies \\
\cline { 1 - 1 } Landslide & & \\
\cline { 1 - 2 } Salinization & & \\
\hline
\end{tabular}

Household data is standardized to calculate the vulnerability. Let Xij is normalized value of household ith $(i=1, n)$ for livelihood group $\mathrm{j}(\mathrm{j}=1, \mathrm{k})$, we have:

$$
X i j=\frac{x i j-x i j(\min )}{x i j(\max )-x i j(\min )}
$$

$x i j$ (min, max): the lowest value and the highest value of household ith in the livelihood group j.

$(-)$ The exposure is calculated by the frequency of occurrence of natural disasters, including hurricanes, floods, droughts, cyclones, salinization and landslides. The exposure of the livelihood group $j(E j)$ is the average frequency of natural disasters after normalization. Sensitivity is calculated by 4 indices: percentage of depended population, the rate of the population is illiterate and the rate of the female population, the size of households is normalized.

(-) Sensitivity of household $i$ (Si) in the livelihood group $j$ is the average of the indices. Sensitivity of the livelihood group $\mathrm{j}$ is calculated using the following formula:

$$
S j=\frac{\sum_{i=1}^{n} S i}{n}
$$

(-) The adaptation of the $i^{\text {th }}$ household is calculated as follow:

$A C i=\frac{P i+A i+h i+k i}{4}$

Adaptability of each household is calculated by the following indices:

- Poverty index $\mathrm{Pi}$ (poor, $\mathrm{Pi}=1$, not poor, $\mathrm{Pi}=0$; neer poor, $\mathrm{Pi}=0.5$ )

- Property Index (Ai) is calculated as follows:

$\mathrm{Ai}=\frac{1}{0.2 * \mathrm{DT}+0.3 * \mathrm{TV}+0.5 * \mathrm{XM}}$

Where: DT is number of phone, TV is number of television, $\mathrm{XM}$ is number of motorcycles in household $\mathrm{i}$.

- Housing structure (firm house, $h=0$; semi-permanent, $h=0.5$; temporary, $h=1$ ).

- Family planning does not adapt to climate change? (Yes, $\mathrm{k}=0$; Do not know, $\mathrm{k}=1$ ).

Livelihood adaptive capacity of groups $\mathrm{j}$ is calculated as follows: $A C j=\frac{\sum_{i=1}^{n} A C i}{n}$.

Livelihood vulnerability of group $\mathrm{j}$ is calculated as follows: $V j=\frac{E j+S j+A C j}{3}$.

\section{Results}

The main livelihoods of residents in Nghia Hung district are cultivation and aquaculture. Cultivation and aquaculture account for about $44 \% \%$ and $9 \%$, respectively (Figure 3 )

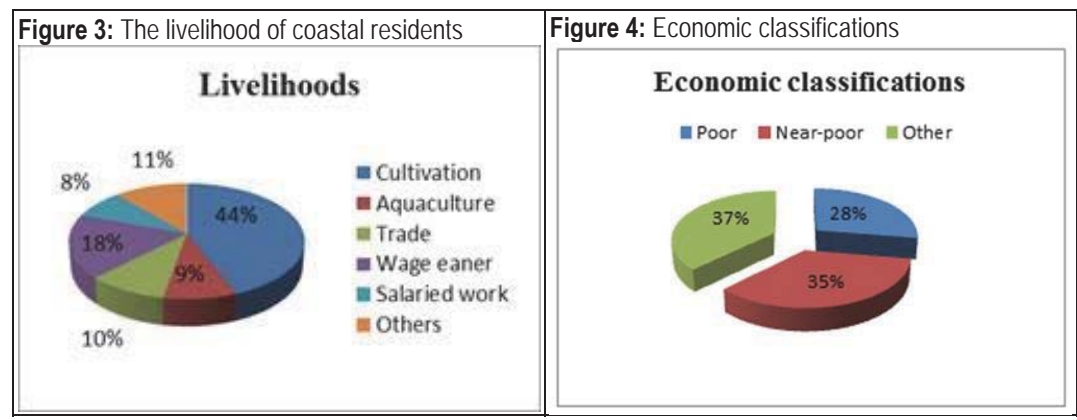

Source: Calculate by authors 
According to the surveyed people, there are $20.25 \%$ of the households living in temporary shelters, $51.90 \%$ in semipermanent houses, and only $27.85 \%$ in firm houses. The study reveals that majority of the population cannot afford the cost of basic decent standard of living. Only $24.05 \%$ of the households use freshwater but water treatment is often simple which filtered via sand and gravel. There are $43.04 \%$ of households lacking water in the summer time. $68.35 \%$ of respondents claimed the quality of the local water supply has been changed, $94.44 \%$ of them said that the quality of the supplied water is worst and nearly non drinkable. About $84.81 \%$ of surveyed households responded that they have got access to information of calamity mitigation plan. However, only about $2.53 \%$ households took part in the community based disaster management training. As a result, they have not taken any measures to mitigate the impacts of climate change on their daily lives (for examples on health, farming activities or access to clean drinking water). It is also noticeable that most of the respondents have heard about climate change and its impact on human society from the local government and electronic media, even though many of them are illiterate (Figure 5). In fact media is not only playing social responsibility to develop awareness of climate change but also assisting to develop the bridge between local observations and global climate change phenomenon. Source of the information about calamity and climate change was shown in Figure 5.

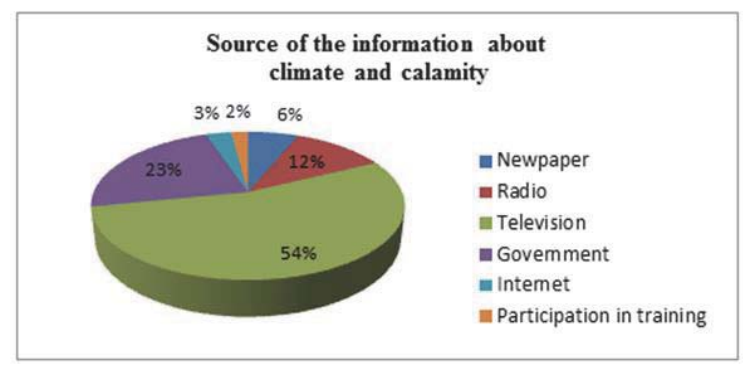

Figure 5: Source of the information

Source: Calculate by authors

People notice about the increase in land, salinity, acidification and decrease in arable land area (over $80 \%$ of respondents answered that the cultivated land area reduced due to soil salinity causes). Regarding to climate, people evaluate the expression of the change of weather is worse and worse such as high temperatures, salinity, acidity, etc. The respondents were asked to indicate their perception about the intensity and frequency of different disaster related to climate change. In response, over $90 \%$ of interviewers response that salinity and high temperature are intensified while over $80 \%$ agree that storm tend to be increased (table 2).

Table 2: The awareness about the frequency of calamity (\%)

\begin{tabular}{|l|c|c|c|c|}
\hline \multirow{2}{*}{ Phenomenon } & \multicolumn{3}{|c|}{ The trend of change } & \multirow{2}{*}{ Not sure } \\
\cline { 2 - 4 } & Increase & Unchange & Decrease & \\
\hline Salinity & 94.94 & 5.06 & 0 & 0 \\
\hline High temperature & 92.41 & 5.06 & 1.27 & 1.26 \\
\hline Low temperature & 87.34 & 0 & 0 & 12.66 \\
\hline Acidity & 84.81 & 3.78 & 0 & 11.41 \\
\hline Storm & 82.28 & 3.78 & 0 & 13.94 \\
\hline Drought & 62.03 & 7.59 & 0 & 30.38 \\
\hline Changeable rain & 56.96 & 6.33 & 0 & 36.71 \\
\hline Flood & 39.24 & 6.33 & 0 & 54.43 \\
\hline
\end{tabular}

Source: Calculate by authors

Respondents were asked to salinity land and acidity land in 10 recents years, $65 \%$ of respondents said that they increased, but on the contrary, $12 \%$ of respondents said that they decreased. In figure 6 , as can be seen that $75 \%$ of surveyed household responded that rice and crop production decreases. 


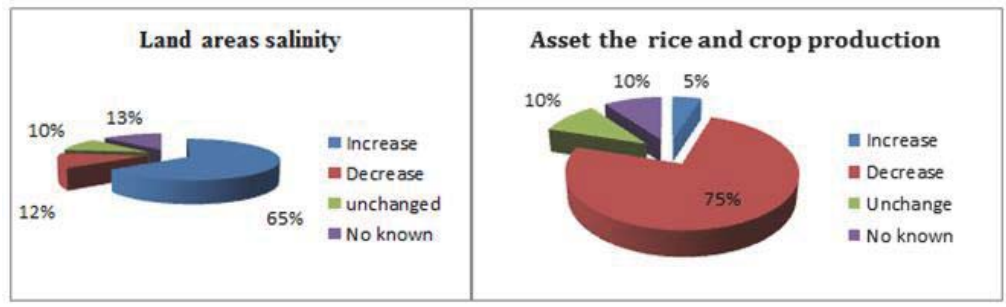

Figure 6: The change in salinity land and acidity land

Source: Calculate by authors

The exposure and adaptive capacity of livelihood groups are showed in figure 7

Figure 7. The exposure and adaptive with climate change

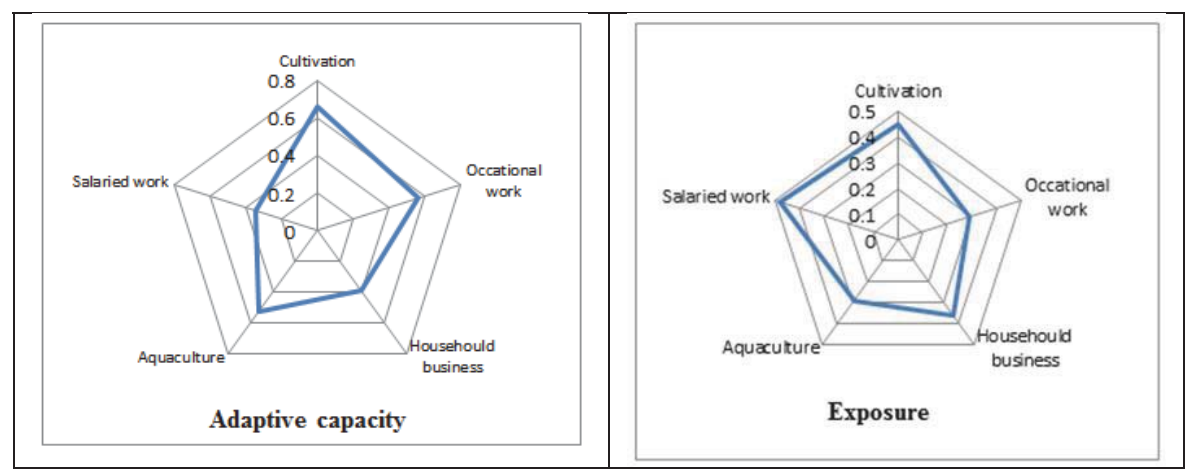

Source: Calculate by authors

The vulnerability indicator calculating result of livelihood groups is showed in table 3.

Table 3: The vulnerability of livelihood groups

\begin{tabular}{|c|l|c|c|c|c|}
\hline No & Livelihood group & Exposure & Sensitivity & Adaptive indicator & V \\
\hline 1 & Cultivation & 0.45 & 0.36 & 0.66 & 0.49 \\
\hline 2 & Occasional work & 0.29 & 0.37 & 0.56 & 0.41 \\
\hline 3 & Household business & 0.36 & 0.37 & 0.39 & 0.37 \\
\hline 4 & Aquaculture & 0.29 & 0.38 & 0.53 & 0.4 \\
\hline 5 & Salaried work & 0.48 & 0.3 & 0.34 & 0.37 \\
\hline
\end{tabular}

Source: Calculate by authors

According to table 3 we can find that the exposure of salaried work is highest (0.48), the next is cultivation (0.45). The adaptive capacity indicator of livelihood groups changes from 0.34 to 0.66 . (The higher value of the index, the lower adaptive capacity it is). The cultivation and aquaculture livelihood groups are often compromised by climate change than others livelihood groups. Combination of these factors (exposure, sensitivity and adaptive capacity) shows that there are differences in the vulnerability of the livelihood groups. These results prove the reality: cultivation groups (vulnerability index is largest with 0.49) and aquaculture generally are more vulnerable by climate change than other livelihood groups such as services and salaried works. One of the reasons is that the cultivation and aquaculture are often more exposed to natural disasters than services and salaried works; and/or the two groups of cultivation and aquaculture generally have adaptive capacity to natural disasters and climate change lower than two groups of services salaried works. The group of 
occasional work is often unstable income and no large assets, resulting in adaptive capacity seems less and high vulnerability index (0.41).

Regarding natural capital, extreme weather events, natural disasters and climate change cause the decline of ecosystems and natural resources. Aquaculture resources and cultivated land are decreasing $(81.19 \%$ of respondents said that the cultivated land decreased causing by salinity). Soil salinity and the drought result in effective cultivation of crops. Diversity of aquaculture resources serious declines. Changing livelihood resources, livelihood strategies of people is more difficult.

Regarding human capital, in the general people's awareness of climate change is not high; people just hear about the climate change and do not concern this issue. Access to the media is relative: mainly through television, through access to newspapers, radio, while access to internet or loudspeakers is limited. On the other hand, people's health is threatened by the risk of quality water. Water sources are seriously polluted because of water salinity and acidity; water is yellow, but not treated and filtered carefully. Poor women do not have stable income generating activities; they are mainly hired labor with limited employment opportunities and do not have large assets. Elderly and children are limited resistance. Meanwhile, climate change and natural disasters affect life, health and property.

In term of social capital, promoting the power of the community in business cooperation is extremely important when a business partnership will leverage the strengths of each household as capital, technology, idle labor. However, the cooperation of the people's livelihood in the Rang Dong is relatively low. Most people do not have much knowledge and skills to perform various livelihood strategies to adapt to climate change. The training of people to share experience and knowledge has been limited and not been promoted. Most of the people interviewed said that they did not participate in training and dissemination of knowledge about the phenomenon of natural disasters unusual to enhance the experience of precautions that easily and efficiently reduces risks caused by climate change.

Regarding financial capital, according to statistics about the feeling of the people interviewed $63 \%$ of households are classified as poor and near-poor. However, observations of people's life and answers of $24 \%$ of these being permanent housing show that they should not be considered poor. The adaptive capacity of farming livelihood groups is highest (0.66). This proves that the adaptive capacity of this livelihood group is the lowest. Causes are the precarious livelihoods, dependence on agriculture; disaster risk should be regular crop loss and famine. Income helping to pay living expense is low and insufficient. The adaptive capacity of the high- wage group $(A C=0.56)$. This suggests that livelihood groups surveyed employed have capacity to adapt to climate change and natural disasters lower. This result is quite consistent with the fact that the respondents in the group hired mainly those with low levels of education, not vocational training (without qualification). They usually do the short - term or seasonal jobs in the area or in the vicinity. On the other hand, the group of employed households usually has low capacity to adapt to climate change and natural disasters due to their poor economic conditions, low education levels and job stability is often reason why these households have no strategy to adapt to climate change and natural disasters. Most people in surveyed area live without savings.

About physical capital, in terms of the mitigation assets in the coastal region, the number of households which do not have boats accounts for 100\%. Among 79 households, only 4 have first aid kit and 60 with motorcycles. Most households have television, radio, flashlight, etc. Adaptive capacity index of the salaried working group is the lowest paid (0.34), which proves that this group has high adaptive capacity. This is consistent with the fact that households in this group have televisions, motorcycles, and houses with permanent structures. While people in the cultivation group mainly have houses with temporary, semi-permanent structures with less assets, so the adaptability of the group is low, corresponding to the adaptive capacity index (0.66).

\section{Discussion}

People's awareness in Rang Dong town about climate change is at level of general knowledge and they do not clearly understand what climate change is. Some people understand that climate is changing due to natural variation. They heard about climate change mainly through television. In fact the mass media are very influential tools for widening public awareness of environmental issues, including climate change (Slovic et al. 2000). In Vietnam, media is playing very active role to educate the mass people by broadcasting feature films and drama. Print and electronic media are also facilitating dialogues among various stakeholders to take action to mitigate the impact of climate change. Ahsan and Brandt (2014) also reveal that though a large number of farmers in Bangladesh are illiterate, yet they most of them came to know about the climate change and its negative impact of human society from media. In fact environmental journalists are working hard to build the awareness about the climate change both in developed and developing parts of the world. When asked about the strategies to minimize the adverse impact of climate change on agriculture, aquaculture and other livelihood activities, most of the respondents answered that they had no idea about the mitigation process. However, 
people were aware of the trend of extreme weather events, as well as its impact of those events on livelihoods. Adaptation with the changed climatic condition is the best policy to mitigate the impact of climate of change in human society. Resilience building management can increase the adaptation capacity of the climate affected population. However, where studied people had no clue or idea how to adapt to climate change, in such cases governmental and NGOs interventions are prerequisite. For the cases like Rang Dong Town, Vietnam not only requires climate adaptive infrastructure but also programs to develop human capacity to combat against climate change and reduce vulnerability. For instance, coastal areas are expected to be more vulnerable to the effects of wind via storm surges (Philippart et al. 2011) which has negative effect on coast aquaculture like mussel and shrimp farming. Therefore farmers may provide proper training how to make more strong dykes with locally available low cost ingredients.

Climate change is happening and seriously impacts on living and production. Climate change increases the vulnerable context. The vulnerable context could be expressed in natural shock (due to natural disasters, climate) and the trend. Natural shock can be listed as high temperature, drought, salinity, acidity and storms. Salinity and the drought lead to ineffective yield. To increase the productivity, people need to use fertilizer and pesticides, but investment capital remains a challenge. As a result, people's income from rice farming is always precarious, unstable, and depends greatly on the water which can wash salt or financial resources, etc. Hurricane and floods have negative impacts on people's life and property. Therefore, floods affect the livelihood resources in the short term, and salinity and acidity affect livelihoods in the long term. There is a tendency that there is a loss of natural aquatic resources and arable land. In interviews, many people in Rang Dong town confirmed that there used to be abundance and diversity of local fisheries resources but currently it seriously falls. Livelihood resources are changing, and livelihood strategies of the Rang Dong town are also changing, which is reflected in the occupational structure. In that structure, crops and livestock farming are the most vulnerable sectors because of its dependents on resources being sensitive with weather conditions. Area of source water salinity and acidity is relatively large, and unusual temperature and droughts have been more frequently seen in recent year's day.

Cultivation group's exposure to natural disaster is relatively high. Especially cultivation exposed highly to the two types of natural disasters: storms and saltwater intrusion. Employee group has low exposure. It can be explained by their nomad nature of the work. That makes them less exposed to natural disasters and climate change in the area they live. Salaried group was exposed highly to the issue. It can be due to the frequent access to information from the media, the internet should assess the frequency of weather events, natural disasters based on more rational. Sensitivity of livelihoods do not have many disparities because the rate of women, the rate of the depended population and so on are non-specific nature of each category of livelihoods.

Sensitivity of the salaried work group is lowest. It could be explained that this group have lower literacy rate than other groups. Group livelihood which is based on farming and aquaculture depends on natural conditions of weather. When climate changes significantly, the phenomenon of disasters and erratic weather happens, natural resources are declined including increasing land salinity, acidity and reducing agricultural land causing the serious effects such as crop failure, pest and disease, affecting the development cycle of crops and crop yields decrease markedly. In addition, aquaculture is inevitable to impacts caused by climate change. So, coastal livelihoods are highly sensitive to the effects of natural disasters and climate change.

General adaptability of livelihood of people in Rang town is not high. The adaptive capacity of livelihoods ranged from 0.34 to 0.66 . The houses at the Rang Dong town, Nghia Hung district is largely substandard, narrow. Therefore, when there is a storm or natural disaster, the house does not get from the threat of natural phenomena. Obviously physical conditions are more restrictive, reducing the ability to cope with natural disasters. Insufficient livelihoods capital resilience to the negative impact of this phenomenon making livelihoods, and lives of people is vulnerable by natural disasters and climate change phenomenon.

\section{References}

Ahsan, D. and U. S. Brandt (2014). Climate change and coastal aquaculture farmers' risk perceptions: experiences from Bangladesh and Denmark. Journal of Environmental Planning and Management: 1-17.

Dasgupta, S., B. Laplante, C. Meisner, D. Wheeler and J. Yan (2009). The impact of sea level rise on developing countries: a comparative analysis. Climatic Change 93(3-4): 379-388.

DFID (2001), "Sustainable Livelihoods Guidance Sheets", DFID Report

ECLAC (2011). An assessment of the economic impact of climate change on the agriculture sector in Guyana, United Nation.

Folke, C., S. Carpenter, T. Elmqvist, L. Gunderson, C. S. Holling and B. Walker (2002). "Resilience and Sustainable Development: Building Adaptive Capacity in a World of Transformations. AMBIO: A Journal of the Human Environment 31(5): 437-440.

Folke, C., T. Hahn, P. Olsson and J. Norberg (2005). ADAPTIVE GOVERNANCE OF SOCIAL-ECOLOGICAL SYSTEMS. Annual 
Review of Environment and Resources 30(1): 441-473.

Giang, L. T. (2005). Damage cause by strong win and wind loads standard for building in Vietnam. Kanagawa, Tokyo Polytechnic University: 29.

Harmeling, S. (2012). Global climate risk index 2012: who suffers most from extreme weather events? weather-related loss events in 2010 and 1991 to 2010. Bonn, Germany, Germanwatch: 28pp.

Holling, C. S. (1973). Resilience and Stability of Ecological Systems. Annual Review of Ecology and Systematics 4(1): 1-23.

IPCC (2001). Climate Change 2001: Impacts, Adaptation and Vulnerability.

Maplecroft (2012). Climate Change Vulnerability Index 2012.

Neil Adger, W. (1999). Social Vulnerability to Climate Change and Extremes in Coastal Vietnam. World Development 27(2): 249-269.

Nielsen, M., L. Ravensbeck and R. Nielsen (2014). Green growth in fisheries. Marine Policy 46(0): 43-52.

Österblom, H., A. Merrie, M. Metian, W. J. Boonstra, T. Blenckner, J. R. Watson, R. R. Rykaczewski, Y. Ota, J. L. Sarmiento, V. Christensen, M. Schlüter, S. Birnbaum, B. G. Gustafsson, C. Humborg, C.-M. Mörth, B. Müller-Karulis, M. T. Tomczak, M. Troell and C. Folke (2013). Modeling Social-Ecological Scenarios in Marine Systems. BioScience 63(9): 735-744.

Österblom, H., M. Sissenwine, D. Symes, M. Kadin, T. Daw and C. Folke (2011). Incentives, social-ecological feedbacks and European fisheries. Marine Policy 35(5): 568-574.

Ostrom, E. (2009). A general framework for analyzing sustainability of social-ecological systems. Science 325(5939): 419-422.

Philippart, C. J. M., R. Anadón, R. Danovaro, J. W. Dippner, K. F. Drinkwater, S. J. Hawkins, T. Oguz, G. O'Sullivan and P. C. Reid (2011). Impacts of climate change on European marine ecosystems: Observations, expectations and indicators. Journal of Experimental Marine Biology and Ecology 400(1-2): 52-69.

Slovic, P., J. Monahan and D. MacGregor (2000). Violence Risk Assessment and Risk Communication: The Effects of Using Actual Cases, Providing Instruction, and Employing Probability Versus Frequency Formats. Law and Human Behavior 24(3): 271-296.

Yusuf, A. A. and H. A. Francisco (2009). Climate Change Vulnerability Mapping for Southeast Asia. Singapore, Economy and Environment Program for Southeast Asia (EEPSEA): 26. 